\title{
Process Approach to Management of Modern Organizations
}

\author{
Yulia Lisichkina \\ Financial University under the Government of the Russian Federation \\ Moscow, Russia \\ e-mail: ljulia@mail.ru
}

\begin{abstract}
This article presents the fundamental principles of implementing the Process approach as the framework of all modern systems of an organizational operations' management. The absence of an understandable and structured description of the "Process approach to an organization's management" leads to an array of misapprehensions among top managers and even among analysts. This consequently leads to disappointment in the application of the Process approach following abortive attempts to implement it.
\end{abstract}

Keywords-organization; system; operations structure; process approach; business processes.

\section{THE PROCESS APPROACH PRINCIPLE}

The economic relationship, shaping in the course of manufacturing, distribution, exchange and consumption, requires the revision of the principles and methods of an organization's management. Many modern organizations' management system has a clearly defined linear-functional structure "Fig. 1".

This linear - functional structure sets up the division of labor, wherein the linear management groups aim to administer and the functional management groups aim to consult and assist in the development of particular issues and prepare relevant decisions and programs. The organizational structure of an enterprise has subdivisions carrying out specific functions.

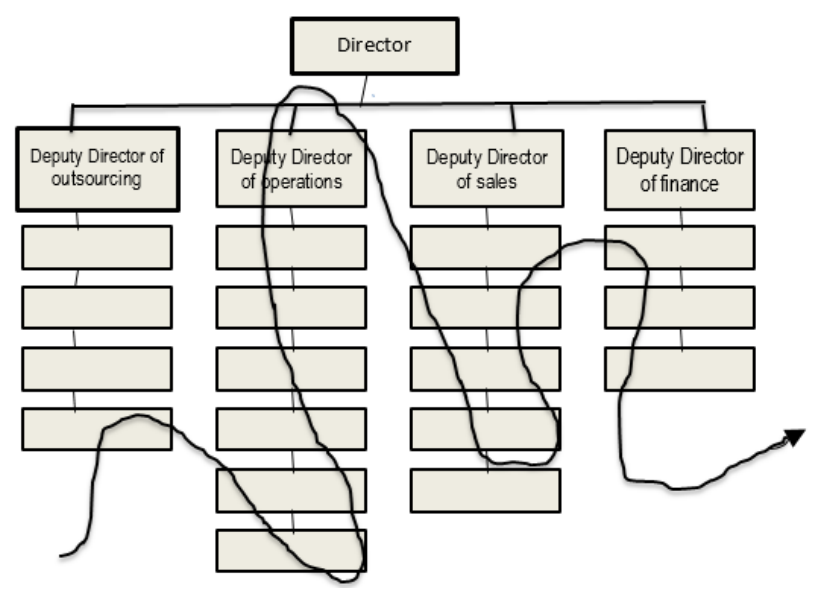

Fig. 1. An enterprise's organizational structure and business processes direction
The linear-functional attitude of such management is not contradictive and perfectly fits many forms of organizational systems. For instance, in military institutions, such a welldefined multilevel linear-functional management structure is justified by the relations of subordination and specific set goals [2].

Note that in actual practice activities are performed only within the linear-functional hierarchy. It penetrates an organization through the complex system of business processes that, in most cases, nobody manages, and for which nobody is personally responsible.

The Process approach to the corporate governance forms the background of all modern management systems. The absence of an understandable and structured description of the "Process approach to corporate administration" system causes an array of misapprehensions among top managers and even among analysts, and consequently leads to a disappointment in the Process approach following the failure of its implementation.

\section{Key AND SuPPORTING PROCESSES}

There are control, key (main, operational) and supporting (ancillary) processes.

The key processes are in charge of proper delivery of goods and services while the control and supporting processes form an organization's structure. Examples of this are the sales and purchasing process, the process of a new product design and its roll out, and the process of customer servicing.

Generally, there is no particular list of business processes - each organization has its individually tailored business processes.

\section{Business Process As CENTRAL CoRE OF ThE PROCESS APPROACH}

The idea of presenting an organization as a defined set of business processes in terms of its operations management started to spread in the end of 1980s. Many globally renowned organizations began to resolve these issues for themselves and to prove practically the worth, efficiency, economy and progressiveness of the transition to the 
customer-oriented production and the process-oriented operations management structure.

"Fig.2" describes the main types of business processes of an organization.

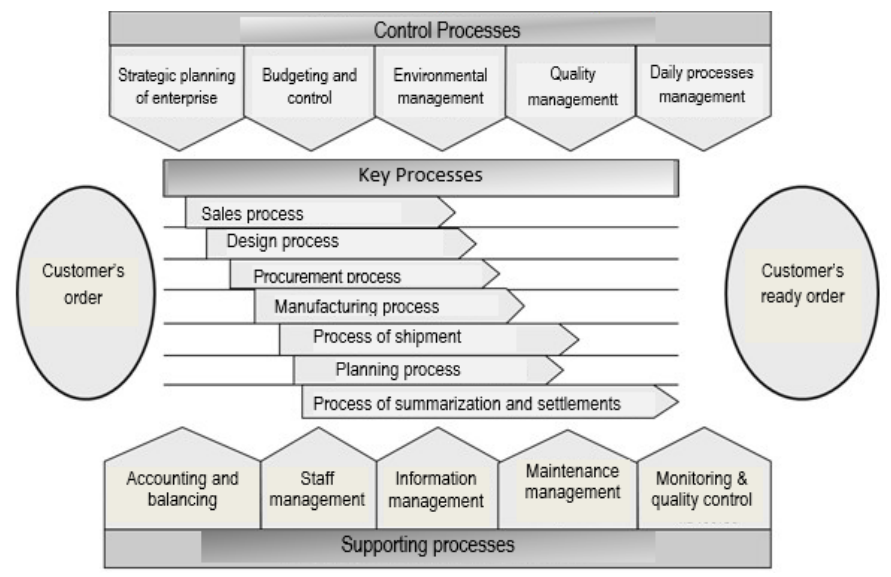

Fig. 2. Main types of business processes at an organization.

The Process approach, the identification of business processes, and their analysis and evaluation provide a tremendous potential capacity for improving an organization's competitiveness and its overall performance. The basic advantages of such an approach can be outlined in the up-to-date optimization of both the processes (in terms of their arrangement, synchronization and consistency) and the resources involved in the business process [3]. The management process, which targets the net result assessed by the consumer, becomes apparent as well.

The diagram "Fig.3" visualizes the business processes.

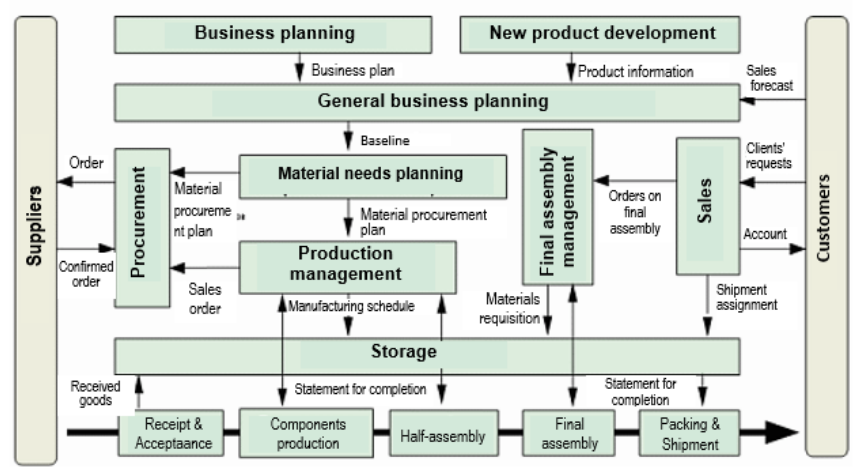

Fig. 3. Example diagram of an organization's business process

The diagram includes figures that describe many processes. The diagram is especially useful for mapping simple business processes, for example, such as the process of a proposal development, presented in "Fig.4".

There are business processes in any community regardless of its size or industry. If they are distinctly expressed and assessed, accordingly improved and regularly streamlined, an organization can be flexible to market conditions and adjust to external conditions-- a key factor in its business success [4].

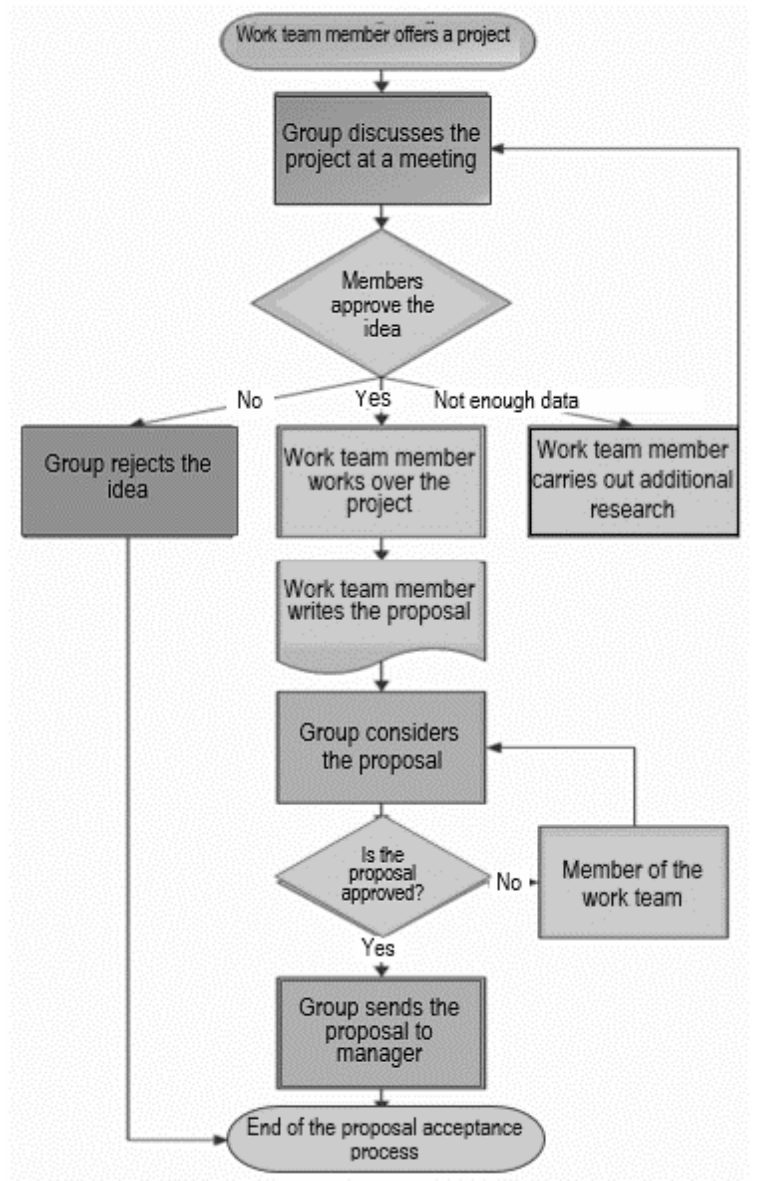

Fig. 4. Template diagram of a proposal development process.

The concept of the business process is the heart of the Process approach to management that has become increasingly popular lately. This approach regards an organization as a system of interrelated processes and provides a company with an opportunity to increase the transparency of the organizational structure, to define the areas of responsibility and to create a system of team motivation.

\section{APPLICATION OF THE PROCESS APPROACH AT AN ORGANIZATION}

The Process approach is applied in order to establish the horizontal and flexible relations in an organization. By having its subdivisions and staff engaged in one process, the organization is able to autonomously coordinate their work within the process and deal with emerging problems. The Process approach to management is instrumental in the prompt addressing of emerging issues and the influencing of those issues outcomes.

The Process approach to the corporate governance is the framework of all modern management systems, including delegation of powers and responsibilities through business processes that suppose a sustainable (routine) business, transforming resources (inputs) into results (outputs). 
The Process approach implies the availability of key elements, the lack of which makes its implementation impossible at an organization "Fig.5" [1].

These key elements are [5]:

- Process input;

- Process output;

- $\quad$ Resources and technologies;

- "Owner" of the process;

- Process consumers and suppliers;

- Process performance;

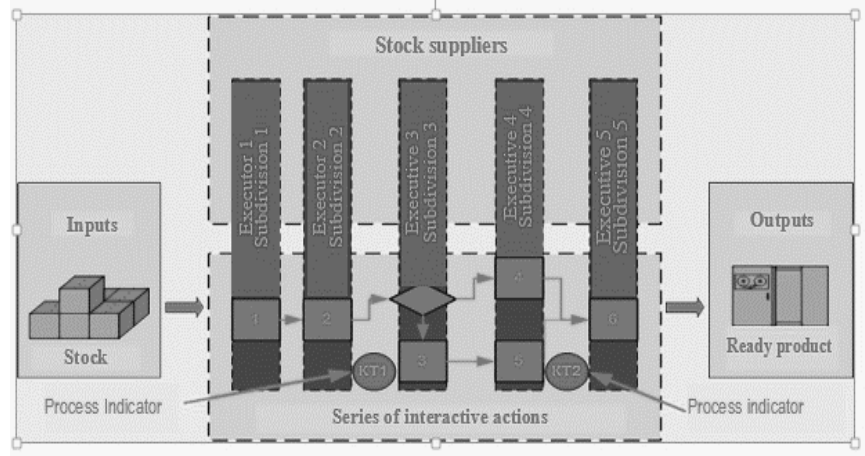

Fig. 5. Process approach elements.

The process inputs are the elements that are undergoing changes in the course of performing operations. As far as inputs, the Process approach considers the stock, equipment, documentation, various information, staff, finances etc.

The outputs of the process present the expected results for which various steps are taken. A tangible product or various kinds of services or information alike can be the output.

Each process must have suppliers and consumers. The suppliers ensure the process' input elements, and the consumers are interested in getting the output elements.

The Process approach suggests the detection of a troubled business process and its participants, the appointment of one of the members of the business process as the "Owner" and the transfer of the power and responsibilities to him to manage this business process. A matrix organization emerges under the systematic activities management. The member of the business process reports to the functional manager and to the "Owner" of the business process, owing to the concurrent application of two approaches to the regular activities management: Functional and Process.

The system of the Process approach to management suggests the availability of the following subsystems:

- A specific business process - the subject of management with identified system boundaries (the context - the environment; subsystems and in-system components; consumed stock; achieved results and such).
- The Key Performance Indicators (KPI), including their planning and control system - the system of measured performance indicators, picturing the performance data and efficiency of the business process, which are used for its management (planning, control, motivation).

- The business process Owner - the member of the business process, to whom the management powers and responsibility are transferred.

- The business process regulations - the description of the object of management to the extent necessary for all parties involved.

- The system of the business process members' motivation on the achievement of its results.

The development and implementation of the Process approach to management is quite a difficult and resourceintensive challenge. In this context, it should be applied only to a limited number of the most problematic and key business processes. Presentation of all business processes of an organization is a difficultly implemented task. Particularly, it is impossible to apply the Process approach to all processes at an organization. In the process of decision-making on utilization of the Process approach, it is necessary to consider the achieved effect against its cost.

\section{IMPLEMENTATION OF THE PROCESS APPROACH}

Finally, it should be mentioned that the implementation even of some of the Process approach subsystems significantly enhances the management system's performance and efficiency. The business process' description and its analysis leads to the information interchange between its members, provides the possibility of forming a correct and shared understanding of the business process, and the resolving of the most systemic and behavioral problems. This underlines the indisputable advantage of the Process approach.

\section{REFERENCES}

[1] Samostroenko G.M., The Process approach to management of lending efficiency at a commercial bank. Yu. A. Volobuyeva, FGBOU VPO "Gosuniversitet - UNPK", FGBOU VPO "Oryol State University", 2014, No.9 (272), pp. 57-64.

[2] Sheyer A.V., Business processes. Main definitions. Theory. Methods, 2nd edition revised and enlarged. M.: Vest'-MetaTekhnologia, 1999, p. 173.

[3] Dzhumigo N.A., Methodological basis of the business processes management at an organization, Izvestia of the Altai State University, Barnaul, Altai State University, 2006, pp. 33-36.

[4] Vlasova A.V., Improvement based on the process approach Komarinsky Yu.A., The collection of the Conference "Quality in production and social and economic systems", M.: OAO "United Aircraft Corporation" MAI, 2014, pp. 58-61.

[5] Krasnozhenova G.F., The Problems of improving the managers training in the conditions of the Russian economy modernization, Bulletin of the Moscow State Linguistic University. M.: Moscow State Linguistic University, 2011, No.612, pp. 31-38. 
[6] Lisichkina Yu.S., The business processes management of modern organization. Economy and management: Problems, Solutions. M.:

Publishing House "Nauchnaya biblioteka", 2015, No.8, pp. 86-91. 